\title{
Metabolic syndrome amongst adults in Jordan: prevalence, trend, and its association with socio-demographic characteristics
}

\author{
Kamel Ajlouni ${ }^{1}$, Yousef Khader ${ }^{2 *}$, Mohamad Alyousfi3 ${ }^{3}$, Mohannad Al Nsour ${ }^{4}$, Anwar Batieha ${ }^{5}$ \\ and Hashem Jaddou ${ }^{5}$
}

\begin{abstract}
Background: Multiple epidemiological studies were conducted amongst a variety of ethnic groups and showed discrepancies in the prevalence of metabolic syndrome (MeS) and its individual components. This study aimed to determine the prevalence of MeS in Jordan using both the Adult Treatment Panel Guidelines (ATP III) and the International Diabetes Federation (IDF) criteria. The study also aimed to assess the changes in the prevalence of MeS over time and determine its association with sociodemographic variables.
\end{abstract}

Methods: Data from the 2017 Cardiovascular Disease Risk Factors Survey were used for this study. Socio-demographic and clinical data were collected using a structured questionnaire. Blood samples were taken for biochemical measurements. Furthermore, anthropometric characteristics were measured by the same team of trained field researchers. A sample of 4,056 individuals aged between 18 and 90 years was included in this study. The findings from the 2017 survey were compared with the findings of a 2009 survey that adopted the same methods and procedures.

Results: According to the IDF criteria, the crude prevalence of Metabolic syndrome was $48.2 \%$ (52.9\% among men and $46.2 \%$ among women; $p<0.001)$. Using the ATP III criteria, the prevalence was $44.1 \%(51.4 \%$ among men and $41 \%$ among women, $\mathrm{p}<0.001)$. The age-standardized prevalence rate of metabolic syndrome was $44 \%(95 \% \mathrm{Cl} 42.7,45.4)$ and 39.9\% (95\% CI 39.6, 41.2), according to both the IDF definition and ATP III criteria, respectively. The Kappa measure of agreement showed excellent agreement between the two definitions $(k=81.9 \%, p<0.001)$. Of all participants, 41.7\% met both the IDF and ATP III diagnostic criteria, $6.6 \%$ met the IDF criteria only, and $2.5 \%$ met the ATP III criteria only. The age-standardized prevalence rate of metabolic syndrome was significantly higher in 2017 (45.7\% in men and 44.5\% in women) than that in 2009 survey (34.6\% in men and 39.8\% in women). Gender, age, occupation, region, and marital status were significantly associated with metabolic syndrome.

Conclusions: The prevalence of metabolic syndrome in Jordan is considerably high and it is increasing. Healthy lifestyle programs encouraging appropriate dietary habits and physical activity are strongly recommended in Jordan.

Keywords: Metabolic syndrome, Diabetes, Obesity, Hypertension

*Correspondence: yskhader@just.edu.jo

2 Department of Public Health, Jordan University of Science and Technology, P.O.Box 3030, Irbid 22110, Jordan

Full list of author information is available at the end of the article

\section{Background}

Non-communicable diseases (NCDs) are emerging as a global health concern with more remarkably increasing trends in low and middle-income countries [1]. The Global Burden of Diseases reports have shown that metabolic abnormalities are the most important determinants of NCDs [2]. MeS more strongly predicts cardiovascular 
diseases and increases the risk of developing diabetes mellitus and chronic kidney disease than its individual components do [3, 4]. There is an escalating concern regarding $\mathrm{MeS}$ in the past few years due to multiple factors such as epidemiologic transition, life-style changes, and the burden of nutrition disorders. However, confusion regarding MeS still exists due to the lack of a unified definition, the debates about its etiology and pathogenesis, and the lack of a consensus protocol for its treatment [2, 3, 5-7]. In 2006, the International Federation for Diabetes (IDF) demonstrated a standard definition for MeS as "a cluster of the most dangerous heart attack and cardiovascular diseases risk factors" [3]. This definition addresses both clinical and research needs, and it provides suitable and accessible tools for diagnosing $\mathrm{MeS}$ status.

The prevalence of MeS has been increasing worldwide for several decades especially in developing countries [8]. It is still hard to provide an accurate estimate of MeS prevalence due to the variety of definitions used. For instance, the prevalence ranges from $10-84 \%$ across different countries, ethnic groups, gender, and age groups. Multiple epidemiological studies were conducted among a variety of ethnic groups and showed discrepancies in the prevalence of $\mathrm{MeS}$ and its individual components [9, 10].

Jordan is a lower middle income country in the Eastern Mediterranean Region. According to the United Nations data, its population is estimated to be $10,203,134$ as of mid-2020. In 2009, a survey was conducted in Jordan and showed that the age-standardized prevalence rate of MeS was $38.0 \%$ using the IDF criteria. The importance of studying the prevalence and trend of MeS stems from the fact that it could potentially be used as an adequate index for detecting people who are at a high risk of NCDs and other cardiovascular diseases [2]. Therefore, a similar survey was conducted within the same population in 2017. This study aimed to determine the prevalence of $\mathrm{MeS}$ in Jordan using the Adult Treatment Panel III (ATP III) and IDF criteria, to assess the changes of MeS prevalence over time, and to determine its association with sociodemographic variables.

\section{Methods}

\section{Study design and sampling}

A survey was conducted among Jordanian adults over a period of four months in the year 2017. The survey methods and procedures were described and detailed in other publications $[11,12]$ and they were similar to those that had been used in the previously conducted 2009 survey [13]. A multistage cluster sampling approach, adopting the probability proportional to size random selection method, was used to ensure the adequate coverage of the entire target population. A city/village was selected from each of the 12 governorates of Jordan. The sample of households was chosen in two stages. In the first stage, well-defined geopolitical areas (clusters) were selected from each city/village. At least one cluster was selected from each city/village randomly using computer-generated random numbers. The second stage of household selection involved choosing a random sample of households from a household list within a selected area. The households from each cluster were selected at random using a systematic sampling technique. A team of two persons (a female and a male) visited members of the selected households. After explaining the study to them, they were asked to visit the health center, while fasting on a given day. Subjects were also asked not to take their medications on the day of their visit and to bring them to the health center. Subjects aged $\geq 18$ years were eligible for inclusion in the study. To encourage participation, the team worked on weekends and holidays and provided free transportation for those who asked for it.

The total sample size selected was 4056 participants with an overall response rate of $78.1 \%$. Using this sample size and assuming that the prevalence of $\mathrm{MeS}$ is $50 \%$, the power of the study to estimate the prevalence of MeS, within a margin of error of $5 \%$ at the alpha level of 0.05 , exceeds $95 \%$.

The study was approved by the Ethical Committee at the National Center for Diabetes, Endocrinology, and Genetics, Amman, Jordan (Ethical code: 1/2015). An informed consent was obtained from each participant. Data were treated with strict confidentiality and used only for scientific purposes.

\section{Data collection}

Trained interviewers administered a comprehensive and structured questionnaire specifically prepared for the purpose of the study. The main data obtained included sociodemographic variables, diabetes, and other cardiovascular disease risk factors. Blood pressure was measured in a standardized way by trained researchers similar to what has been done in the 2009 survey [13]. Three blood samples were drawn from a cannula inserted into the antecubital vein and used for the different laboratory measurements. Tubes containing sodium fluoride potassium oxalate were used for glucose measurement. Samples were centrifuged within one hour at the survey site and then transferred by separate labeled tubes in iceboxes to the central laboratory of the National Center of Diabetes, Endocrinology, and Genetics in Amman, Jordan. All biochemical measurements were carried out by the same team of laboratory technicians and using the same method throughout the study period. Fasting plasma, glucose, and lipid measurements were performed 
according to the manufacturers' instructions, using the COBAS autoanalyzer (Roche Diagnostics, Basel, Switzerland).

\section{Anthropometric measurements}

Using digital scales (seca), the subjects' weight was measured while they were minimally clothed and not wearing shoes. Their height was measured using a portable stadiometer (seca 214 portable stadiometer). Their Body Mass Index (BMI) was calculated as weight in kilograms divided by height in meters squared [14]. Their waist circumference (WC) was measured at the midway between the iliac crest and the lower rib margin, over light clothing, using un-stretchable tape (seca 203), and without any pressure to the body surface. Their Waist to Hip Ratio (WHR) was calculated as WC divided by hip circumference, and their waist to height (WHtR) was calculated as WC divided by height in centimeters. All measurements were taken by the same team of well-trained persons using the same tools.

\section{Definitions}

Being overweight or obese was classified according to the definition of overweight (BMI of $25-29.9 \mathrm{~kg} / \mathrm{m}^{2}$ ) and obesity (BMI of $30 \mathrm{~kg} / \mathrm{m}^{2}$ or more) in adults [15]. MeS was defined according to IDF criteria and ATP III diagnostic criteria. Diabetes was defined according to IDF Diabetes Atlas 8th Edition Diagnostic Criteria [16].

\section{Statistical analysis}

Data were entered and analyzed using the Statistical Package for Social Sciences Software "SPSS IBM version 24". The raw data file for 2009 were re-analyzed using the same variable definitions to assess the time-trends in $\mathrm{MeS}$ prevalence. Proportions were used to estimate the prevalence of MeS. Overall and age-specific prevalence rates were obtained and reported separately for each gender. The age-standardized prevalence rates were derived in order to permit comparison between the different surveys and to allow comparison with studies in other countries, using the world population as a standard population. Chi-square was used to compare proportions. Multivariate binary logistic regression was conducted to determine factors associated with MeS. A p-value of less than 0.05 was considered statistically significant.

\section{Results}

\section{Socio-demographic characteristics}

This study included 4056 participants [1193 (29.4\%) men and $2863(70.6 \%)$ women] aged 18 years or more. About $26.5 \%$ of the sample were between 40 and 49 years old. Men were significantly older than women; the mean (SD) age was 47.5 (14.6) year for men and 42.2 (13.7) year for women $(\mathrm{p}<0.001)$. The majority of participants (94\%) were Jordanians while $6 \%$ were Syrians. Table 1 shows the socio-demographic characteristics of participants according to gender. The sample demographic breakdown (age, education, and nationality) is similar to national data.

\section{Anthropometric and clinical characteristics}

The mean anthropometric and biochemical characteristics for Jordanians are shown in Table 1. There was a significant difference in the majority of studied parameters. The mean (SD) of BMI was $29.5(6.0) \mathrm{kg} / \mathrm{m}^{2}$, thus being significantly higher in women than in men $(30(6.4) \mathrm{kg} /$ $\mathrm{m}^{2}$ vs. 28.4 (4.8) $\left.\mathrm{kg} / \mathrm{m}^{2} ; p<0.001\right)$. The mean systolic and diastolic blood pressure, mean fasting blood glucose, and mean triglyceride were significantly higher in men than in women. On the other hand, women showed significantly higher cholesterol, HDL, and LDL levels than men.

\section{The prevalence rate of MeS}

The crude prevalence of MeS was 48.2\% (52.9\% among men and $46.2 \%$ among women; $\mathrm{p}<0.001$ ) according to the IDF criteria. According to the ATP III criteria, the prevalence was $44.1 \%$ (51.4\% among men and $41 \%$ among women, $\mathrm{p}<0.001)$. The age-standardized prevalence rate of MeS was $44 \%$ (95\% CI 42.7\%, 45.4\%) and 39.9\% (95\% CI $39.6 \%, 41.2 \%)$ using the IDF definition and ATP III criteria, respectively. The kappa measure of agreement showed excellent agreement between the two definitions $(\mathrm{k}=81.9 \%, \mathrm{p}<0.001)$. Of all participants, $41.7 \%$ met both the IDF and ATP III diagnostic criteria, $6.6 \%$ met the IDF criteria, and $2.5 \%$ met the ATP III criteria only. Tables 2 and 3 show the crude and age-standardized sex-specific prevalence rates of $\mathrm{MeS}$ and its individual components using the ATP III and IDF criteria.

\section{Age-specific prevalence rate of MeS}

The age-specific prevalence of MeS for men and women is shown in Figs. 1 and 2 using the IDF definition and ATP III definition, respectively. According to both definitions, the prevalence of $\mathrm{MeS}$ increased significantly with age in both men and women $(\mathrm{P}<0.001)$. With the IDF definition, the prevalence rose from $13.1 \%$ for men aged $18-29$ years to $66.9 \%$ for those aged $60-69$ years. Then, it declined to $60.6 \%$ in those aged 70 years and above. The prevalence rose from $11.7 \%$ in women aged 18-29 years to $85.2 \%$ in women aged $60-69$ years. Then, it declined to $81.0 \%$ in those aged 70 years and above.

With the ATP III definition, the prevalence rose from $10.5 \%$ for men aged $18-29$ years to $73.4 \%$ for those aged 60-69 years and then declined to $56.4 \%$ in those aged 70 years and above. While the prevalence rose from $8 \%$ in women aged $18-29$ years to $80.2 \%$ in women aged 
Table 1 Socio-demographic, anthropometric and clinical characteristics of 4056 participants according gender, Jordan 2017

\begin{tabular}{|c|c|c|c|c|}
\hline & $\begin{array}{l}\text { Men } \\
(n=1193) n(\%)\end{array}$ & $\begin{array}{l}\text { Women } \\
(n=2863) n(\%)\end{array}$ & $\begin{array}{l}\text { Total } \\
(\mathrm{N}=4056) \mathrm{n}(\%)\end{array}$ & $p$-value* \\
\hline Age (year) & & & & $<0.001$ \\
\hline $18-29$ & $155(13)$ & $582(20.4)$ & $737(18.2)$ & \\
\hline $30-39$ & $180(15.1)$ & $626(21.9)$ & $806(19.9)$ & \\
\hline $40-49$ & $313(26.3)$ & $758(26.5)$ & $1071(26.5)$ & \\
\hline $50-59$ & $294(24.7)$ & $557(19.5)$ & $851(21)$ & \\
\hline $60-69$ & $154(12.9)$ & $249(8.7)$ & $403(10)$ & \\
\hline$\geq 70$ & $95(8)$ & $84(2.9)$ & $179(4.4)$ & \\
\hline Marital status & & & & $<0.001$ \\
\hline Single & $144(12.1)$ & $462(16.1)$ & $606(14.9)$ & \\
\hline Married & $1049(87.9)$ & $2401(83.9)$ & $3450(85.1)$ & \\
\hline Nationality & & & & 0.942 \\
\hline Jordanian & $1117(94)$ & $2669(93.9)$ & 3786 (93.9) & \\
\hline Syrian & $71(6)$ & $173(6.1)$ & $244(6.1)$ & \\
\hline Smoking status & & & & $<0.001$ \\
\hline Current & $395(33.1)$ & $189(6.6)$ & $584(14.4)$ & \\
\hline Past & $206(17.3)$ & $46(1.6)$ & $252(6.2)$ & \\
\hline \multirow[t]{2}{*}{ Never } & $592(49.6)$ & $2628(91.8)$ & $3220(79.4)$ & \\
\hline & Mean (SD) & Mean (SD) & Mean (SD) & \\
\hline Body mass index $\left(\mathrm{kg} / \mathrm{m}^{2}\right)$ & $28.4(4.8)$ & $30(6.4)$ & $29.5(6)$ & $<0.001$ \\
\hline Waist circumference $(\mathrm{cm})$ & $98.9(15.1)$ & $92.7(16.6)$ & $94.6(16.4)$ & $<0.001$ \\
\hline Waist to hip ratio & $0.94(0.08)$ & $0.85(0.1)$ & $0.88(0.1)$ & $<0.001$ \\
\hline Waist to height ratio & $0.57(0.08)$ & $0.58(0.1)$ & $0.58(0.1)$ & $<0.001$ \\
\hline Systolic blood pressure (mmHg) & $127(19.6)$ & $118.3(19.7)$ & $120.9(20.1)$ & $<0.001$ \\
\hline Diastolic blood pressure (mmHg) & $79.5(11.7)$ & 75 (11.6) & $76.3(11.8)$ & $<0.001$ \\
\hline Fasting blood glucose (mg/dL) & $123.7(58.6)$ & $106.9(41.6)$ & $111.9(47.9)$ & $<0.001$ \\
\hline Total cholesterol (mg/dL) & $193.3(45.8)$ & $197.5(41.7)$ & $196.2(43)$ & $<0.05$ \\
\hline $\mathrm{HDL}(\mathrm{mg} / \mathrm{dL})$ & $38.2(9.5)$ & $48.6(12.3)$ & $45.6(12.5)$ & $<0.001$ \\
\hline $\mathrm{LDL}(\mathrm{mg} / \mathrm{dL})$ & $125(37.3)$ & $126.9(36.3)$ & $126.3(36.6)$ & 0.135 \\
\hline Triglyceride (mg/dL) & $203.8(209.3)$ & $147.3(110.6)$ & 164 (149) & $<0.001$ \\
\hline
\end{tabular}

* Chi-Square test is used to compare proportions between men and women and independent $t$ test is used to compare means between men and women

60-69 years, it declined to $77.4 \%$ in those aged 70 years and above.

\section{Prevalence of MeS syndrome according} to socio-demographic characteristics

Tables 4 and 5 show the prevalence of MeS according to socio-demographic characteristics using the IDF and ATP III criteria, respectively.

\section{Prevalence rate of individual components of MeS}

The prevalence of obesity in Jordan was $44.7 \%$ and it was significantly higher in women (48.2\%) compared to men $(36.1 \%)(\mathrm{p}<0.001)$. The age-standardized prevalence of obesity was $41.4 \%$ (95\% CI 39.9\%, 42.9\%). Among components of MeS, abdominal obesity was the most prevalent metabolic abnormality. According to the IDF definition, women had a higher prevalence of abdominal obesity (77.8\%) compared to men (67.3\%) $(\mathrm{p}<0.001)$. Low HDL cholesterol was the second most common metabolic abnormality in both men and women. Elevated Triglycerides and low HDL level prevalence rates were $41.8 \%$ and $59.1 \%$, respectively. The difference between men and women was statistically significant in elevated triglycerides level $(\mathrm{p}<0.001)$ but not in low HDL level $(\mathrm{p}=0.057)$. High fasting blood sugar prevalence rates were $37.5 \%$ and $28.8 \%$ according to both the IDF and the ATP III definitions. Men recorded a significantly higher prevalence of high fasting blood sugar using both the IDF and ATP III definitions (47.4\% and $40 \%$ respectively) compared to women (33.4\% and $24.2 \%$ respectively). The relative frequencies of the number of metabolic abnormalities according to the IDF and the ATP III measurements are shown in Figs. 3 and 4. 
Table 2 The sex-specific crude prevalence rates of Metabolic syndrome and its individual components in Jordan, using the ATP III and IDF definitions, Jordan 2017

\begin{tabular}{|c|c|c|c|c|}
\hline & Men number (\%) & Women number (\%) & Total number (\%) & $P$-value* \\
\hline \multicolumn{5}{|l|}{ Metabolic syndrome } \\
\hline IDF definition & $625(52.9)$ & $1300(46.2)$ & $1925(48.2)$ & $<0.001$ \\
\hline ATP definition & $608(51.4)$ & $1154(41)$ & $1762(44.12)$ & $<0.001$ \\
\hline \multicolumn{5}{|l|}{ Central obesity } \\
\hline IDF definition & $797(67.3)$ & $2193(77.8)$ & $2990(74.6)$ & $<0.001$ \\
\hline ATP definition & $491(41.5)$ & $1772(62.8)$ & $2263(56.5)$ & $<0.001$ \\
\hline \multicolumn{5}{|l|}{ Body mass index } \\
\hline Obesity & $419(36.1)$ & $1355(48.2)$ & $1774(44.7)$ & $<0.001$ \\
\hline Overweight & $478(41.2)$ & $819(29.1)$ & $1297(32.7)$ & $<0.001$ \\
\hline Elevated triglycerides & $645(54.5)$ & $1031(36.5)$ & $1676(41.8)$ & $<0.001$ \\
\hline Low HDL & $727(61.5)$ & $1644(58.1)$ & $2371(59.1)$ & 0.057 \\
\hline Elevated blood pressure & $647(54.5)$ & 1077 (38.2) & $1724(42.9)$ & $<0.001$ \\
\hline \multicolumn{5}{|l|}{ High fasting blood glucose } \\
\hline IDF definition & $560(47.4)$ & $938(33.4)$ & $1498(37.5)$ & $<0.001$ \\
\hline ATP definition & $476(40)$ & $692(24.2)$ & $1168(28.8)$ & $<0.001$ \\
\hline
\end{tabular}

* Chi-Square test is used to compare prevalence rates of Metabolic syndrome and its individual components between men and women

Table 3 Age standardized sex-specific prevalence rates of metabolic syndrome and its components in Jordan, using ATP III and IDF definitions, Jordan 2017

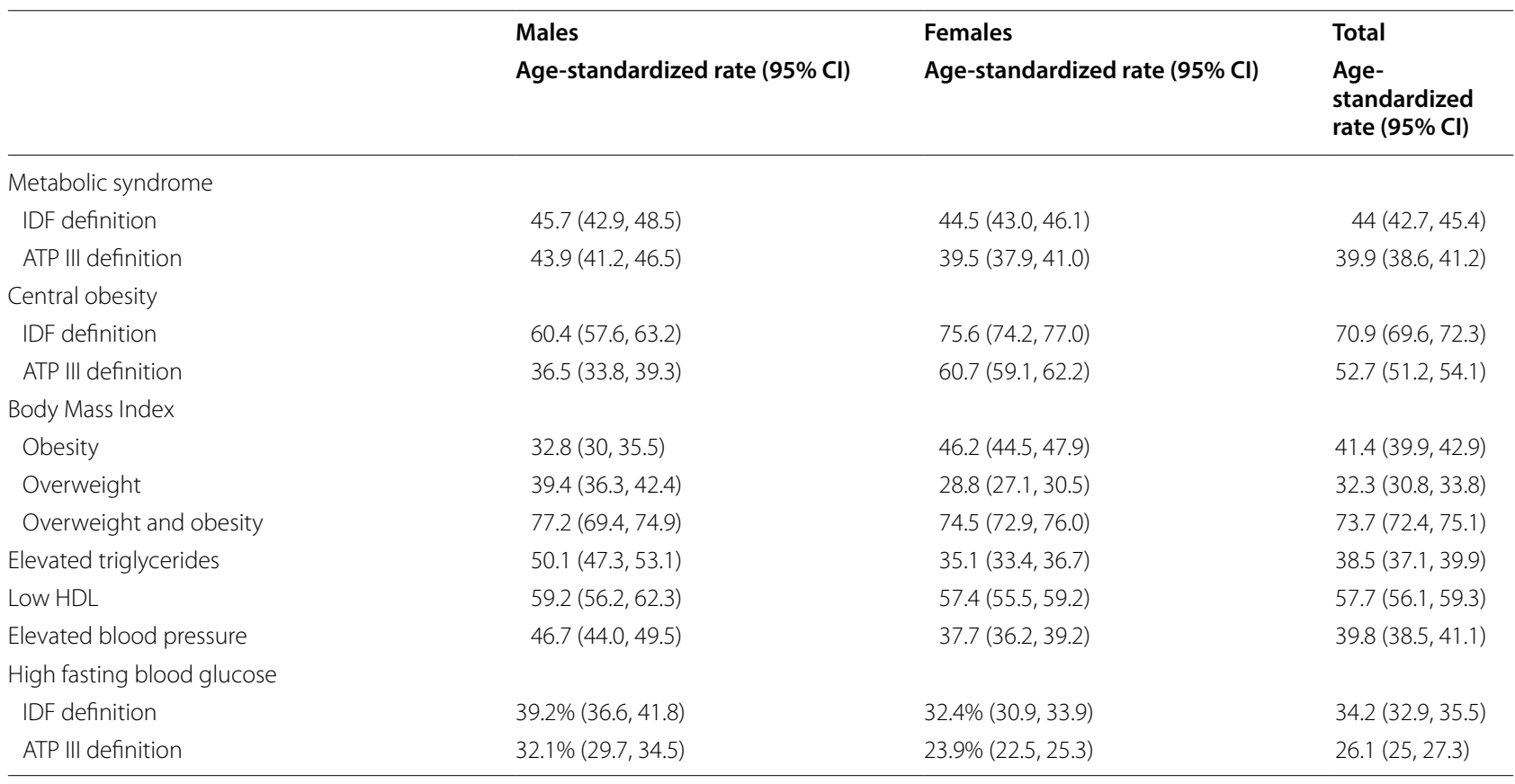

\section{Changes in the MeS Rate between 2009 and 2017}

The 2017 sample had a higher mean age compared to the 2009 sample (43.8 (14.2) year and 41.8 (13.3) years, respectively). A comparison in the sex-specific age-standardized prevalence rates of $\mathrm{MeS}$ between 2009 and 2017 surveys is shown in Table 6. The age-standardized prevalence rate of $\mathrm{MeS}$ was significantly higher in 2017 (45.7\% in men and 44.5\% in women) than in 2009 survey (34.6\% in men and $39.8 \%$ in women). Among men and women, the age-standardized rates of abdominal obesity and high fasting blood glucose were higher in 2017 than those in 2009. 


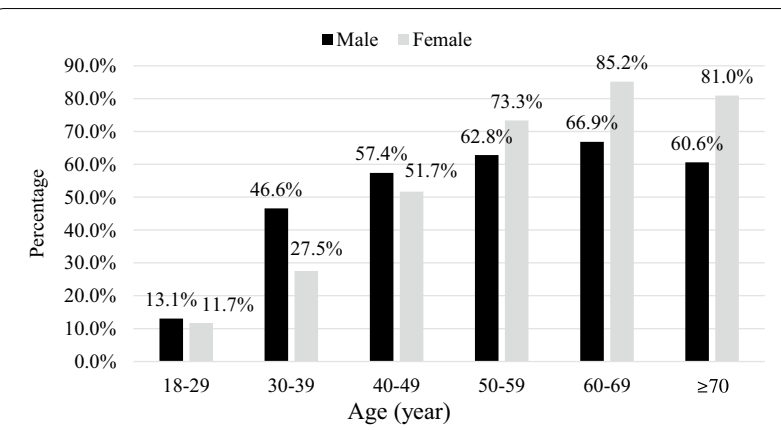

Fig. 1 Age-specific prevalence of metabolic syndrome using the IDF definition in Jordan

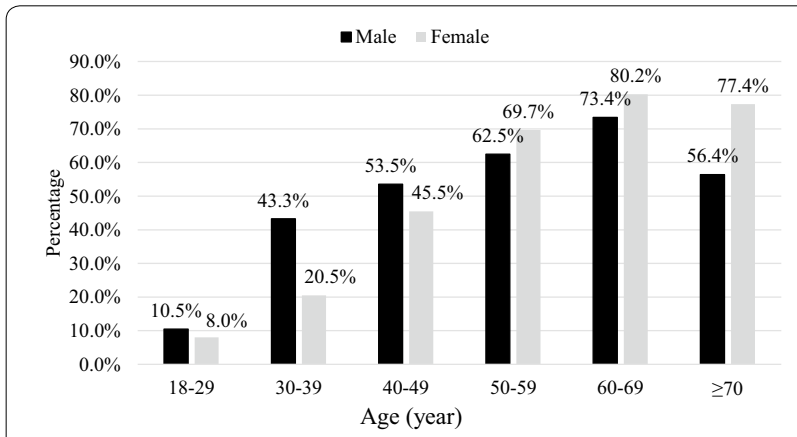

Fig. 2 Age-specific prevalence of metabolic syndrome using the ATP III definition in Jordan

The 2009 survey showed higher prevalence rates of elevated blood pressure, elevated triglycerides, and low HDL levels.

\section{Factors associated with MeS}

A multivariate logistic regression analysis was conducted to determine factors associated with $\mathrm{MeS}$ (Tables 7 and 8). Defined by the IDF diagnostic criteria, many factors were associated with MeS including gender, age, occupation, region, and marital status.

Women had increased odds of MeS compared to men $(\mathrm{OR}=1.42 ; 95 \%$ CI 1.1, 1.83,p $<0.05)$. Increased age was significantly associated with increased odds of MeS. Unemployed persons were more likely to have $\mathrm{MeS}(\mathrm{OR}=1.38$; 95\% CI 1.02, 1.86,p $<0.05)$ compared to those who had fieldwork. Compared to those who were living in the north of Jordan, those who lived in the mid-region of Jordan were less likely to have metabolic syndrome $(\mathrm{OR}=0.66$ : 95\% CI 0.54, 0.80, $\mathrm{p}<0.001)$. Married people were more than twice $(\mathrm{OR}=2.26)$ as likely to have Metabolic syndrome compared to singles.

\section{Discussion}

This study reports the prevalence of MeS and its individual components among adults in Jordan using the IDF and the ATP III definitions and it compares the findings with the findings of a previous study conducted in 2009. Two diagnostic criteria were used to define MeS to facilitate the comparisons between the study findings and the findings of other studies that reported prevalence estimates using different definitions. The sample of Jordanians who participated in the study was representative of the general population of Jordan as the distribution of their relevant demographic factors was similar to that of the general population.

When the IDF diagnostic criteria was used, the agestandardized prevalence rates of $\mathrm{MeS}$ in Jordan was $44 \%$ ( $45.7 \%$ in men and $44.5 \%$ in women). This rate is slightly higher than what had been reported in the US population (40\%) [17] and much higher than that in the Australian population (29.1\%) [10]. The European population recorded rates from 10 to $30 \%$ [10], and the Iranian people recorded a rate of $37.4 \%$ [18]. Compared to Arab countries, the age-standardized prevalence of $\mathrm{MeS}$ was higher than the prevalence in Saudi Arabia in 2009 and 2014 (31.6\% and $28.3 \%$, respectively) [19, 20]. However, Aljabri et al. in 2018 reported a high prevalence rate (64.4\%) among Saudi population [21]. The prevalence rates among the populations of Qatar and Kuwait were $37 \%$ and $36.2 \%$, respectively [22, 23], while the MeS prevalence in the United Arab Emirates using the IDF criteria was reported in two studies conducted in 2008 and 2012 as $40.5 \%$ and $48.7 \%$, respectively $[24,25]$. The Lebanese population had a lower prevalence $(31.2 \%)$ than that found in Jordan [26]. The prevalence in Jordan is very close to the prevalence reported among Turkish adults (44\%) [18].

According to the ATP III criteria, the age-standardized prevalence rate of $39.9 \%$ (95\% CI 38.6, 41.2) was lower than the prevalence defined by the IDF criteria. The two definitions almost have the same components, but the difference in prevalence was mainly linked to the difference in waist circumference. Abdominal obesity is considered an obligatory component for the IDF definition in contrast to being one of five components for the ATP III definition.

Compared to the US population, Jordan had a higher $\mathrm{MeS}$ prevalence than what had been reported in the US in $2014(33.8 \%)$ using the ATP III criteria [27]. Also, it was higher than that in the Australian population (19.3\%) [10], the Turkish population (36.6\%) [18], and the European population (ranges from 10-30\%) [10]. Compared to Arab countries, Jordan had a higher prevalence of $\mathrm{MeS}$ defined by the ATP III criteria than most Arab countries including Lebanon (26.4\%) [28], Oman (23.6\%) [29], 
Table 4 Prevalence of metabolic syndrome by age categories, smoking status, marital status, region and nationality among Jordanians using IDF definition, Jordan 2017

\begin{tabular}{|c|c|c|c|c|c|c|}
\hline \multirow[t]{3}{*}{ Variables } & \multicolumn{2}{|l|}{ Men } & \multirow[t]{3}{*}{$P$ value* } & \multicolumn{2}{|l|}{ Women } & \multirow[t]{3}{*}{$P$ value* } \\
\hline & No & Yes & & No & Yes & \\
\hline & Number (\%) & Number (\%) & & Number (\%) & Number (\%) & \\
\hline Age (years) & & & $<0.001$ & & & $<0.001$ \\
\hline $18-29$ & $133(86.9)$ & $20(13.1)$ & & $506(88.3)$ & $67(11.7)$ & \\
\hline $30-39$ & $95(53.4)$ & $83(46.6)$ & & $445(72.5)$ & $169(27.5)$ & \\
\hline $40-49$ & $132(42.6)$ & $178(57.4)$ & & $364(48.3)$ & $390(51.7)$ & \\
\hline $50-59$ & $109(37.2)$ & $184(62.8)$ & & $145(26.7)$ & $399(73.3)$ & \\
\hline $60-69$ & $51(33.1)$ & $103(66.9)$ & & $36(14.8)$ & $207(85.2)$ & \\
\hline$\geq 70$ & $37(39.4)$ & $57(60.6)$ & & $16(19)$ & $68(81)$ & \\
\hline Smoking status & & & $<0.001$ & & & 0.05 \\
\hline No & $280(47.6)$ & $308(52.4)$ & & $1413(54.6)$ & $1174(45.4)$ & \\
\hline Past & 68 (33.3) & $136(66.7)$ & & $20(43.5)$ & $26(56.5)$ & \\
\hline Current & $211(53.8)$ & $181(46.2)$ & & $81(43.5)$ & $105(56.5)$ & \\
\hline Marital status & & & $<0.001$ & & & $<0.001$ \\
\hline Single & $126(89.4)$ & $15(10.6)$ & & $380(83.3)$ & $76(16.7)$ & \\
\hline Married & $433(41.5)$ & $610(58.5)$ & & $1134(48)$ & $1229(52)$ & \\
\hline Region & & & $<0.001$ & & & $<0.001$ \\
\hline North & $179(46)$ & $210(54)$ & & $459(50.4)$ & $451(49.6)$ & \\
\hline Middle & $261(55.8)$ & $207(44.2)$ & & $753(58.5)$ & $534(41.5)$ & \\
\hline South & $119(36.4)$ & $208(63.6)$ & & $302(48.6)$ & $320(51.4)$ & \\
\hline Nationality & & & 0.045 & & & 0.043 \\
\hline Jordanian & $517(46.7)$ & $591(53.3)$ & & $1422(54.2)$ & $1204(45.8)$ & \\
\hline Syrian & $41(57.7)$ & $30(42.3)$ & & $81(47.1)$ & 91 (52.9) & \\
\hline
\end{tabular}

* Chi-Square test is used to compare prevalence rates of Metabolic syndrome according to studied variables for men and women

Tunisia (31.2\%) [30], the United Arab Emirates (22\%) [31], Qatar (26.5\%) [32], Yemen (23.8\%) [33], and Kuwait (18.3\%) [34].

On the other hand, two studies conducted in Saudi Arabia utilizing ATP III definition reported prevalence rates similar to that of Jordan. The first study in 2009 revealed a prevalence of $39.9 \%$ and an earlier study conducted in 2005 reported a prevalence of $39.3 \%$ [19, 35]. A study in the United Arab Emirates reported a prevalence of 50.3\% in 2012 which is higher than Jordan's prevalence rate [24]. Another study conducted in 2008 revealed a prevalence of $39.6 \%$ which is approximately similar to the rate found in this study [25]. The considerable discrepancy in the prevalence of $\mathrm{MeS}$ among and across different nations and populations could be a result of the integration of genetics, environmental aspects and factors, epidemiological transition, and differences in lifestyle. Differences in the definition used and differences in the sampling approaches and procedures might also explain some of the variations in the prevalence rates [23-25].

Obesity and central obesity may have an effect on this variation across different nations and populations, as central obesity is the most observed component among those diagnosed with MeS. Obesity increases the risk of developing multiple metabolic abnormalities including hypertension and insulin resistance which logically lead to developing MeS [36]. Consequently, the variation in the MeS prevalence between Jordan and other countries could be explained by the variation in obesity prevalence. In Jordan, the prevalence of obesity was $41.4 \%$ which is higher than what had been reported in Egypt (30.1\%) [37], Lebanon (28.2\%) [38], Syria (38.2\%) [39], Saudi Arabia (33\%) [40], United Arab Emirates (32.3\%) [41], Qatar (35.4\%) [42], Yemen (8.8\%) [43], and Tunisia (25.4\%) [44]. On the other hand, multiple studies in Saudi Arabia, Kuwait, and Libya revealed either higher or similar obesity prevalence rates compared to Jordan. Nadira AlBaghli reported an obesity prevalence of $43.8 \%$ in Saudi Arabia [45]. The prevalence amongst Kuwaitis was estimated as $47.5 \%$ [23], while the prevalence was $42.4 \%$ in Libya [46].

The prevalence of $\mathrm{MeS}$ increased with age in both men and women, using the IDF and ATP III diagnostic criteria. The sharp increase happened during their second decade of life, especially for men. This could be explained by age-related changes in the body, insulin sensitivity, 
Table 5 Prevalence of metabolic syndrome by age categories, smoking status, marital status, region and nationality among Jordanians using ATP III definition, Jordan 2017

\begin{tabular}{|c|c|c|c|c|c|c|}
\hline \multirow[t]{3}{*}{ Variables } & \multicolumn{2}{|l|}{ Men } & \multirow[t]{3}{*}{$P$ value* } & \multicolumn{2}{|l|}{ Women } & \multirow[t]{3}{*}{$P$ value* } \\
\hline & No & Yes & & No & Yes & \\
\hline & Number (\%) & Number (\%) & & Number (\%) & Number (\%) & \\
\hline Age (years) & & & $<0.001$ & & & $<0.001$ \\
\hline $18-29$ & 137 (89.5) & $16(10.5)$ & & $527(92)$ & $46(8)$ & \\
\hline $30-39$ & $101(56.7)$ & $77(43.3)$ & & $488(79.5)$ & $126(20.5)$ & \\
\hline $40-49$ & $144(46.5)$ & $166(53.5)$ & & $411(54.5)$ & $343(45.5)$ & \\
\hline $50-59$ & $110(37.5)$ & $183(62.5)$ & & $165(30.3)$ & $379(69.7)$ & \\
\hline $60-69$ & $41(26.6)$ & $113(73.4)$ & & 48 (19.8) & $195(80.2)$ & \\
\hline$\geq 70$ & 41 (43.6) & $53(56.4)$ & & $19(22.6)$ & 65 (77.4) & \\
\hline Smoking status & & & $<0.001$ & & & $<0.05$ \\
\hline Never & $295(50.2)$ & $293(49.8)$ & & $1541(59.6)$ & $1046(40.4)$ & \\
\hline Past & $76(37.3)$ & $128(62.7)$ & & $24(52.2)$ & $22(47.8)$ & \\
\hline Current & $205(52.3)$ & $187(47.7)$ & & $95(51.1)$ & 91 (48.9) & \\
\hline Marital status & & & $<0.001$ & & & $<0.001$ \\
\hline Single & $126(89.4)$ & 15 (10.6) & & $398(87.3)$ & $58(12.7)$ & \\
\hline Married & $450(43.1)$ & $593(56.9)$ & & $1262(53.4)$ & 1101 (46.6) & \\
\hline Region & & & $<0.001$ & & & $<0.001$ \\
\hline North & $169(43.4)$ & $220(56.6)$ & & $517(56.8)$ & $393(43.2)$ & \\
\hline Middle & $267(57.1)$ & $201(42.9)$ & & $821(63.8)$ & $466(36.2)$ & \\
\hline South & $140(42.8)$ & $187(57.2)$ & & $322(51.8)$ & $300(48.2)$ & \\
\hline Nationality & & & $<0.001$ & & & 0.081 \\
\hline Jordanian & $527(47.6)$ & $581(52.4)$ & & 1555 (59.2) & $1071(40.8)$ & \\
\hline Syrian & 48 (67.6) & $23(32.4)$ & & $92(53.5)$ & $80(46.5)$ & \\
\hline
\end{tabular}

* Chi-Square test is used to compare prevalence rates of Metabolic syndrome according to studied variables for men and women

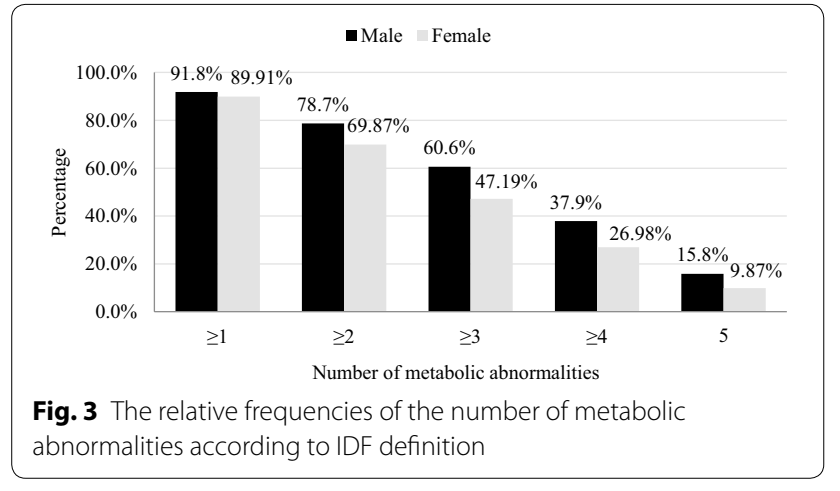

and fat distribution, all of which have been mentioned previously to contribute to the increased prevalence of $\mathrm{MeS}$ with age [47]. Women were observed to have higher MeS prevalence than men after their fourth decade of life. This continuously increasing prevalence in women could be a result of menopause. Menopause was reported to have an association with an increased risk of $\mathrm{MeS}$ and it is affecting all of its components [48]. On the contrary, the decrease in the prevalence among men and women

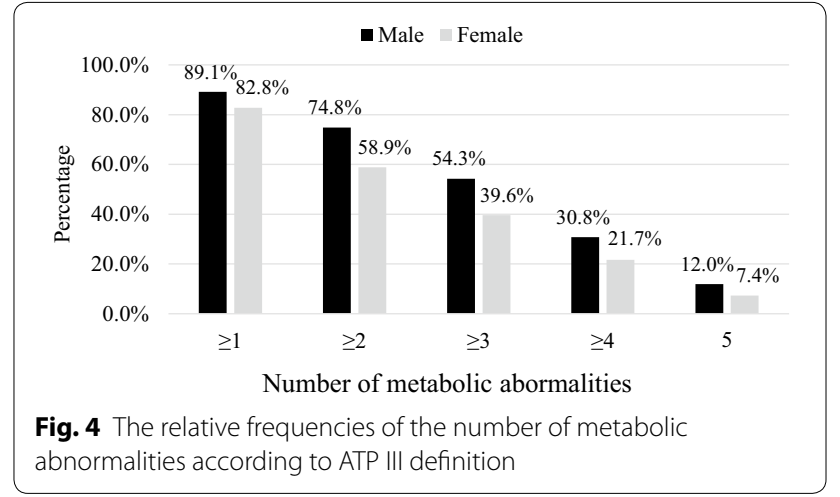

after the sixth decade of life could be due to survival bias, where people affected by $\mathrm{MeS}$ die at a comparatively younger age, which leads to a depletion in the older age categories of affected individuals.

In our study, men had significantly higher MeS prevalence than women using both the IDF and ATP III diagnostic criteria. A study in Saudi Arabia supported our findings [19], while other studies did not $[13,20,47]$. The significant difference between men and 
Table 6 The sex-specific age-standardized prevalence rates of metabolic syndrome according to IDF definition and its individual components in two different periods (2009 and 2017), Jordan

\begin{tabular}{|c|c|c|}
\hline & 2017 & 2009 \\
\hline & $\begin{array}{l}\text { Age-standardized } \\
\text { prevalence rate }(95 \% \\
\mathrm{Cl})\end{array}$ & $\begin{array}{l}\text { Age-standardized } \\
\text { prevalence rate }(95 \% \\
\text { Cl) }\end{array}$ \\
\hline \multicolumn{3}{|c|}{ Metabolic syndrome } \\
\hline Male & $45.7(42.9,48.5)$ & $34.6(31.4,37.8)$ \\
\hline Female & $44.5(43.0,46.1)$ & $39.8(38.1,41.5)$ \\
\hline Total & $44(42.7,45.4)$ & $38.0(36.5,39.5)$ \\
\hline \multicolumn{3}{|c|}{ Central obesity } \\
\hline Male & $60.4(57.6,63.2)$ & $41.5(38.0,45.1)$ \\
\hline Female & $75.6(74.2,77.0)$ & $60.1(58.2,61.9)$ \\
\hline Total & $70.9(69.6,72.3)$ & $55.2(53.5,56.9)$ \\
\hline \multicolumn{3}{|c|}{ High fasting blood glucose } \\
\hline Male & $39.2(36.6,41.8)$ & $28.7(25.8,31.6)$ \\
\hline Female & $32.4(30.9,33.9)$ & $23.9(22.3,25.5)$ \\
\hline Total & $34.2(32.9,35.5)$ & $25.1(23.7,26.4)$ \\
\hline \multicolumn{3}{|c|}{ Elevated blood pressure } \\
\hline Male & $46.7(44.0,49.5)$ & $47.2(43.5,50.8)$ \\
\hline Female & $37.7(36.2,39.2)$ & $38.6(37.0,40.3)$ \\
\hline Total & $39.8(38.5,41.1)$ & $40.2(38.7,41.6)$ \\
\hline \multicolumn{3}{|c|}{ Elevated triglycerides } \\
\hline Male & $50.1(47.3,53.1)$ & $54.4(50.4,58.3)$ \\
\hline Female & $35.1(33.4,36.7)$ & $40.0(38.1,42.0)$ \\
\hline Total & $38.5(37.1,39.9)$ & $42.7(41.0,44.4)$ \\
\hline \multicolumn{3}{|l|}{ Low HDL } \\
\hline Male & $59.2(56.2,62.3)$ & $70.0(66.1,73.8)$ \\
\hline Female & $57.4(55.5,59.2)$ & $64.7(62.7,66.7)$ \\
\hline Total & $57.7(56.1,59.3)$ & $65.7(64.0,67.5)$ \\
\hline $\begin{array}{l}\text { HDL high- } \\
\text { lipoprot }\end{array}$ & & \\
\hline
\end{tabular}

women might be explained by age as men had a significantly higher mean age than women in this study. Age is strongly associated with an increased prevalence of $\mathrm{MeS}[10,13,27,47]$. Subsequently, after adjusting for age, occupation, location, and marital status, women had significantly increased odds of MeS compared to men only using the IDF. The reason might be that women have a significantly higher prevalence of abdominal obesity compared to men. On the other hand, data reported from the National Health and Nutrition Examination Survey (NHANES) among the US population from 2007 to 2014 did not show any significant gender differences [27].

For both men and women, abdominal obesity was the most prevalent component of $\mathrm{MeS}$ using the IDF and ATP III definitions. The prevalence rates of
Table 7 Multivariate logistic regression model of the factors associated with metabolic syndrome, using the IDF criteria, Jordan 2017

\begin{tabular}{|c|c|c|}
\hline & OR $(95 \% \mathrm{CI})$ & P-value* \\
\hline \multicolumn{3}{|l|}{ Gender } \\
\hline Men & 1 (Ref) & \\
\hline Women & $1.42(1.10,1.83)$ & $<0.05$ \\
\hline \multicolumn{3}{|l|}{ Age (years) } \\
\hline $18-29$ & 1 (Ref) & $<0.001$ \\
\hline $30-39$ & $2.53(1.79,3.57)$ & $<0.001$ \\
\hline $40-49$ & $5.78(4.16,8.03)$ & $<0.001$ \\
\hline $50-59$ & $12.44(8.73,17.73)$ & $<0.001$ \\
\hline $60-69$ & $14.54(9.42,22.42)$ & $<0.001$ \\
\hline$\geq 70$ & $10.45(6.26,17.44)$ & $<0.001$ \\
\hline \multicolumn{3}{|l|}{ Occupation } \\
\hline Field Work & 1 (Ref) & $<0.05$ \\
\hline Unemployed & $1.38(1.02,1.86)$ & $<0.05$ \\
\hline Retired & $0.95(0.67,1.35)$ & 0.758 \\
\hline Office Work & $1.01(0.76,1.36)$ & 0.925 \\
\hline \multicolumn{3}{|l|}{ Region } \\
\hline North & 1 (Ref) & $<0.001$ \\
\hline Middle & $0.66(0.54,0.80)$ & $<0.001$ \\
\hline South & $1.14(0.90,1.44)$ & 0.282 \\
\hline \multicolumn{3}{|l|}{ Marital status } \\
\hline Single & 1 (Ref) & \\
\hline Married & $2.26(1.61,3.18)$ & $<0.001$ \\
\hline
\end{tabular}

hyperglycemia, hypertriglyceridemia, and hypertension, despite being less common than abdominal obesity, are still high in this population. Women had a significantly higher crude and age-standardized prevalence rate of obesity using both the IDF and ATP III definitions. The explanation of the large waist circumferences and body mass index in women could be due to the fact that women in Jordan are less likely to participate in physical activity due to cultural and social limitations [47].

The age-standardized prevalence of $\mathrm{MeS}$ in this current study was markedly higher compared to a that in 2009 Jordan study. Also, the age-adjusted prevalence rates of abdominal obesity and hyperglycemia in this present population were higher than those in the 2009 population. On the other hand, lower age-standardized prevalence for low HDL levels was seen in a 2017 survey compared to the 2009 study. These variations in the prevalence could be explained by shifting from traditional dietary habits (a diet rich in fibers, vegetables, fruits, and cereals) to consuming more animal products and junk food, with high amounts of carbohydrates and saturated fats [13]. 


\begin{tabular}{|c|c|c|}
\hline & OR $(95 \% \mathrm{Cl})$ & Pvalue* \\
\hline \multicolumn{3}{|l|}{ Age (years) } \\
\hline $18-29$ & 1 (Ref) & $<0.001$ \\
\hline $30-39$ & $2.65(1.80,3.90)$ & $<0.001$ \\
\hline $40-49$ & $7.00(4.85,10.11)$ & $<0.001$ \\
\hline $50-59$ & $17.11(11.60,25.22)$ & $<0.001$ \\
\hline $60-69$ & $20.62(13.00,32.72)$ & $<0.001$ \\
\hline$\geq 70$ & $12.20(7.18,20.71)$ & $<0.001$ \\
\hline \multicolumn{3}{|l|}{ Occupation } \\
\hline Field Work & 1 (Ref) & $<0.001$ \\
\hline Unemployed & $1.76(1.32,2.35)$ & $<0.001$ \\
\hline Retired & $1.17(0.81,1.68)$ & 0.400 \\
\hline Office Work & $1.14(0.84,1.54)$ & 0.400 \\
\hline \multicolumn{3}{|l|}{ Region } \\
\hline North & 1 (Ref) & $<0.001$ \\
\hline Middle & $0.63(0.52,0.76)$ & $<0.001$ \\
\hline South & $1.10(0.86,1.40)$ & 0.457 \\
\hline \multicolumn{3}{|l|}{ Marital status } \\
\hline Single & 1 (Ref) & \\
\hline Married & $2.00(1.39,2.89)$ & $<0.001$ \\
\hline
\end{tabular}

* $p$-values for adjusted odds ratios from multivariate binary logistic regression

One of the main study limitations is the lack of available data on important predictors of MeS such as physical activity and dietary habits. Such variables are essential to be studied and to be included in the logistic regression model. Future research should consider such variables to determine the best predictors of MeS.

\section{Conclusions}

The prevalence of MeS in Jordan is considerably high, and it is increasing. MeS was associated with gender, age, occupation, region, and marital status. This escalation in $\mathrm{MeS}$ prevalence is assumed to be a result of lifestyle changes and epidemiological transition, unhealthy dietary habits, and lack of exercise. Therefore, healthy lifestyle programs encouraging appropriate dietary habits and physical activity are strongly recommended in Jordan. Once the diagnosis is made, the potential treatment should be proactive and persistent in its goal of reducing the risk of CVD and type 2 diabetes.

\section{Abbreviations}

NCDs: Non-communicable diseases; IDF: International Federation for Diabetes; ATP III: Adult Treatment Panel III; BMI: Body mass index; WC: Waist circumference; WHR: Waist to hip ratio; WHtR: waist to height ratio; HDL: High-Density
Lipoprotein; LDL: Low-Density Lipoprotein; NHANES: National Health and Nutrition Examination Survey.

\section{Acknowledgements}

Not applicable.

\section{Authors' contributions}

$\mathrm{YK}, \mathrm{AB}$, and $\mathrm{HJ}$ : Contributed to study design, data collection, analysis, writing the manuscript. MA and MA: Contributed to data analysis and revising the manuscript. KA: Contributed to study design and writing the manuscript. All authors have read and approved the manuscript.

\section{Funding}

The study was funded by the Research Fund at the Ministry of Higher Education. The funding body provided financial support to conduct the study and has no role in the design of the study and collection, analysis, and interpretation of data and in writing the manuscript.

\section{Availability of data and materials}

The data used to support the findings of this study are available from the corresponding author upon request.

\section{Ethics approval and consent to participate}

The study was approved by the Ethical Committee at the National Center for Diabetes, Endocrinology, and Genetics, Amman, Jordan. An informed consent was obtained from each participant. Data were treated with strict confidentiality and used only for scientific purposes.

\section{Consent for publication}

Not applicable.

\section{Competing interests}

The authors declare that they have no competing interests.

\section{Author details}

${ }^{1}$ The National Center for Diabetes, Endocrinology and Genetics, The Jordan University, Amman, Jordan. ${ }^{2}$ Department of Public Health, Jordan University of Science and Technology, P.O.Box 3030, Irbid 22110, Jordan. ${ }^{3}$ Department of Public Health, Faculty of Medicine, Jordan University of Science \& Technology, Irbid, Jordan. ${ }^{4}$ The Eastern Mediterranean Public Health Network (EMPHNET), Amman, Jordan. ${ }^{5}$ Department of Public Health, Jordan University of Science and Technology Irbid, Irbid, Jordan.

Received: 3 August 2020 Accepted: 5 November 2020

Published online: 18 November 2020

\section{References}

1. Boutayeb A, Boutayeb S. The burden of non communicable diseases in developing countries. Int J Equity Health. 2005;4(1):2.

2. Kelishadi R, Hovsepian S, Djalalinia S, Jamshidi F, Qorbani M. A systematic review on the prevalence of metabolic syndrome in Iranian children and adolescents. J Res Med Sci. 2016;21:90.

3. IDF Consensus Worldwide. Definition of the Metabolic Syndrome. 2006, Available from: https://www.idf.org/e-library/consensus-statements /60-idfconsensus-worldwide-definitionof-the-metabolic-syndrome.html (Accessed August 2, 2020).

4. Khader Y, Khatatbeh M, El-Salem K, Amarin Z, Bateiha A. The metabolic syndrome among patients undergoing cardiac catheterization in Jordan. J Cardiometab Syndr. 2008;3(4):224-8.

5. Alberti KG, Zimmet PZ. Definition, diagnosis and classification of diabetes mellitus and its complications. Part 1: diagnosis and classification of diabetes mellitus provisional report of a WHO consultation. Diabet Med. 1998;15(7):539-53.

6. Balkau B, Charles MA. Comment on the provisional report from the WHO consultation. European Group for the Study of Insulin Resistance (EGIR). Diabet Med. 1999;16(5):442-3.

7. Executive Summary of The Third Report of The National Cholesterol Education Program (NCEP). Expert Panel on Detection, Evaluation, And 
Treatment of High Blood Cholesterol In Adults (Adult Treatment Panel III). JAMA. 2001;285(19):2486-97.

8. Woo KS, Hu YJ, Chook P, Wei AN, Chan R, Yin YH, Celermajer DS. A Tale of Three Gorges in the Yangtze River: Comparing the Prevalence of Metabolic syndrome According to ATPIII, WHO, and IDF Criteria and the Association with Vascular Health in Modernizing China. Metab Syndr Relat Disord. 2019;17(3):137-42.

9. O'neill S, O'driscoll L. Metabolic syndrome: a closer look at the growing epidemic and its associated pathologies. Obes Rev. 2015;16(1):1-12.

10. Nazare JA, Smith JD, Borel AL, Haffner SM, Balkau B, Ross R, Massien C, Alméras N, Després JP. Ethnic influences on the relations between abdominal subcutaneous and visceral adiposity, liver fat, and cardiometabolic risk profile: the International Study of Prediction of Intra-Abdominal Adiposity and Its Relationship With Cardiometabolic Risk/Intra-Abdominal Adiposity. Am J Clin Nutr. 2012 Oct;96(4):714-26.

11. Abujbara M, Batieha A, Khader Y, Jaddou H, El-Khateeb M, Ajlouni K. The Prevalence of Dyslipidemia among Jordanians. J Lipids. 2018;2018:6298739.

12. Khader Y, Batieha A, Jaddou H, El-Khateeb M, Ajlouni K. The performance of anthropometric measures to predict diabetes mellitus and hypertension among adults in Jordan. BMC Public Health. 2019;19(1):1416.

13. Dajani R, Khader YS, Hakooz N, Fatahalla R, Quadan F. Metabolic syndrome between two ethnic minority groups (Circassians and Chechens) and the original inhabitants of Jordan. Endocrine. 2013;43(1):112-9.

14. Cole TJ, Lobstein T. Extended international (IOTF) body mass index cut-offs for thinness, overweight and obesity. Pediatric Obes. 2012:7(4):284-94.

15. World Health Organization. Obesity and overweight 2018, February 16. Available from: https://www.who.int/news-room/fact-sheets/detail/obesi ty-and-overweight (Accessed August 2, 2020).

16. International Diabetes Federation, editor. IDF Diabetes Atlas. 8 ed. Brussels: International Diabetes Federation; 2017.

17. Ford ES. Prevalence of the metabolic syndrome defined by the International Diabetes Federation among adults in the US. Diabetes Care. 2005;28(11):2745-9.

18. Ansarimoghaddam A, Adineh HA, Zareban I, Iranpour S, HosseinZadeh A, Kh F. Prevalence of metabolic syndrome in Middle-East countries: Meta-analysis of cross-sectional studies. Diabetes Metab Syndr. 2018;12(2):195-201.

19. Al-Rubeaan K, Bawazeer N, Al Farsi Y, Youssef AM, Al-Yahya AA, AlQumaidi $\mathrm{H}$, et al. Prevalence of metabolic syndrome in Saudi Arabia - a cross sectional study. BMC Endocr Disord. 2018;18(1):16.

20. Aljohani NJ. Metabolic syndrome: Risk factors among adults in Kingdom of Saudi Arabia. J Fam Community Med. 2014;21(3):170.

21. Aljabri KS, Bokhari SA, Alshareef MA, Khan PM. Prevalence of Metabolic syndrome in Saudi Population. Archives Of Diabetes Obesity. 2018;1(3):45-53.

22. Al-Thani MH, Al-Thani AA, Cheema S, Sheikh J, Mamtani R, Lowenfels $A B$, et al. Prevalence and determinants of metabolic syndrome in Qatar: results from a National Health Survey. BMJ Open. 2016;6(9):e009514.

23. Al Rashdan I, Al Nesef Y. Prevalence of overweight, obesity, and metabolic syndrome among adult Kuwaitis: results from community-based national survey. Angiology. 2010;61(1):42-8

24. Hajat C, Shather Z. Prevalence of metabolic syndrome and prediction of diabetes using IDF versus ATPIII criteria in a Middle East population. Diabetes Res Clin Pract. 2012;98(3):481-6.

25. Malik M, Razig SA. The prevalence of the metabolic syndrome among the multiethnic population of the United Arab Emirates: a report of a national survey. Metab Syndr Relat Disord. 2008;6(3):177-86.

26. Sibai A-M, Obeid O, Batal M, Adra N, El Khoury D, Hwalla N. Prevalence and correlates of metabolic syndrome in an adult Lebanese population. CVD Prevention Control. 2008;3(2):83-90.

27. Shin D, Kongpakpaisarn K, Bohra C. Trends in the prevalence of metabolic syndrome and its components in the United States 2007-2014. Int J Cardiol. 2018;259:216-9.

28. Nasreddine L, Ouaijan K, Mansour M, Adra N, Sinno D, Hwalla N. Metabolic syndrome and insulin resistance in obese prepubertal children in Lebanon: a primary health concern. Ann Nutr Metab. 2010;57(2):135-42.

29. El-Aty MA, Mabry R, Morsi M, Al-Lawati J, Al-Riyami A, El-Sayed M. Metabolic syndrome and Its Components: Secondary analysis of the World Health Survey, Oman. Sultan Qaboos Univ Med J. 2014;14(4):e460-7.

30. Allal-Elasmi M, Taieb SH, Hsairi M, Zayani Y, Omar S, Sanhaji H, et al. The metabolic syndrome: prevalence, main characteristics and association with socio-economic status in adults living in Great Tunis. Diabetes Metab. 2010:36(3):204-8.

31. Khthir R, Espina F. The metabolic syndrome in rural UAE: the effect of gender, ethnicity and the environment in its prevalence. J Metabolic syndrome. 2014;3:159.

32. Bener A, Zirie M, Musallam M, Khader YS, Al-Hamaq AO. Prevalence of metabolic syndrome according to Adult Treatment Panel III and International Diabetes Federation criteria: a population-based study. Metab Syndr Relat Disord. 2009;7(3):221-9.

33. Almikhafy A, Maklady F, Sobhy S, Elsheikh E, Alansi AK. Metabolic syndrome among Yemeni Psysicians in Sana'a. SCU-MJ. 2008;11:31-4.

34. Roshdy R. Prevalence of metabolic syndrome in patients with schizophrenia. MECPsych. 2011;18(2):109-17.

35. Al-Nozha M, Al-Khadra A, Arafah MR, Al-Maatouq MA, Khalil MZ, Khan NB, et al. Metabolic syndrome in Saudi Arabia. Saudi Med J. 2005;26(12):1918-25.

36. Engin A. The Definition and Prevalence of Obesity and Metabolic Syndrome. Adv Exp Med Biol. 2017;960:1-17.

37. Abolfotouh MA, Soliman LA, Mansour E, Farghaly M, El-Dawaiaty AA. Central obesity among adults in Egypt: prevalence and associated morbidity. East Mediterr Health J. 2008;14(1):57-68.

38. Nasreddine L, Naja F, Chamieh MC, Adra N, Sibai AM, Hwalla N. Trends in overweight and obesity in Lebanon: evidence from two national cross-sectional surveys (1997 and 2009). BMC Public Health. 2012;12:798.

39. Fouad M, Rastam S, Ward K, Maziak W. Prevalence of obesity and its associated factors in Aleppo, Syria. Prev Control. 2006;2(2):85-94.

40. Garawi F, Ploubidis GB, Devries K, Al-Hamdan N, Uauy R. Do routinely measured risk factors for obesity explain the sex gap in its prevalence? Observations from Saudi Arabia. BMC Public Health. 2015;15:254.

41. Sulaiman N, Elbadawi S, Hussein A, Abusnana S, Madani A, Mairghani M, et al. Prevalence of overweight and obesity in United Arab Emirates Expatriates: the UAE National Diabetes and Lifestyle Study. Diabetol Metab Syndr. 2017;9:88.

42. Ali FM, Nikoloski Z, Reka H, Gjebrea O, Mossialos E. The diabetes-obesityhypertension nexus in Qatar: evidence from the World Health Survey. Popul Health Metr. 2014;12:18.

43. Gunaid AA. Obesity, overweight and underweight among adults in an urban community in Yemen. East Mediterr Health J. 2012;18(12):1187-93.

44. El Ati J, Traissac P, Delpeuch F, Aounallah-Skhiri H, Beji C, Eymard-Duvernay $S$, et al. Gender obesity inequities are huge but differ greatly according to environment and socio-economics in a North African setting: a national cross-sectional study in Tunisia. PloS one. 2012;7(10):e48153.

45. Al-Baghli NA, Al-Ghamdi AJ, Al-Turki KA, El-Zubaier AG, Al-Ameer MM, Al-Baghli FA. Overweight and obesity in the eastern province of Saudi Arabia. Saudi Med J. 2008;29(9):1319-25.

46. Lemamsha H, Randhawa G, Papadopoulos C. Prevalence of Overweight and Obesity among Libyan Men and Women. Biomed Res Int. 2019;2019:8531360

47. Khader Y, Bateiha A, El-Khateeb M, Al-Shaikh A, Ajlouni K. High prevalence of the metabolic syndrome among Northern Jordanians. J Diabetes Complications. 2007;21(4):214-9.

48. Pu D, Tan R, Yu Q, Wu J. Metabolic syndrome in menopause and associated factors: a meta-analysis. Climacteric. 2017;20(6):583-91.

\section{Publisher's Note}

Springer Nature remains neutral with regard to jurisdictional claims in published maps and institutional affiliations. 